\title{
Sociocultural Framing of 'Ambo-Gbabe' Music Video Campaign in the 2015 Gubernatorial Elections in Lagos State, Nigeria
}

\author{
Koblowe Obono \\ Department of Communication and Language Arts \\ University of Ibadan, Ibadan, Nigeria
}

DOI:10.36108/NJSA/8102/61(0130)

\begin{abstract}
The 2015 Lagos State governorship campaign of the All Progressives Congress (APC) used sociocultural frames conjuring indigeneity and modernity to attract political attention and support. Constructed through religious, economic, cultural and humaninterest frames, a blissful future encapsulating the hopeful ethos of the city was projected. Reflecting and conscientizing their messianic aspirations, this existentialist paradigm attended to the hopes of the people for better living conditions. The article examines and interprets the sociocultural frames in 'Ambo-Gbabe' music video, focusing on context-specific images that reveal the manifesto of Akinwunmi Ambode. The video expressed the political ideas and intentions of the contestant by employing popular, emotional and cultural appeals. A combination of figurative expressions, languages, proverbs, dramaturgy, incantation, rap, and skelewu and shoki dances drew the message closer to the political environment, while the musicology relates to the demographic ecology of Lagos. Using the genre of current street music, the candidate's political vision of populism, collectivism, gender equality and unity in diversity were showcased. The lyrics, sounds and imageries largely conform to the sociodemographic and cultural ideologies of residents. The paper portrays the place of ethnomusicology for political campaign and convergence between politics and performance in popular culture.
\end{abstract}

Keywords: Ethnomusicology, collectivist culture, sociocultural frames, music video campaign, political communication, popular culture, Lagos State elections

\section{Introduction}

The changing socio-political climate in Nigeria is affecting the nature of electioneering. This reflects in the Lagos State governorship campaign of the All Progressives Congress (APC) candidate, Akinwunmi Ambode, who used 'Ambo-Gbabe' music campaign video for this purpose. Deployment of popular music for political communication is vital for persuading, mobilising and empowering the public for informed decision making (Obono, 2017). Configuration of the music stems from a complexity of cultural, contextual and ideological factors. While sociocultural-nuanced music campaign would bring ease of association and assimilation of political messages, it will also inform the thought flow of people within a given location. As a medium of information, campaign music video has potential to form perceptions in an 
entertaining way (Wardani, Listya \& Winarni, 2017). In essence, music has psychological and cognitive effects on the audience (Moore, 2010), hence, its exploitation for electioneering. Indigenous culture, imagery, language, popular music and linguistic forms are utilised to communicate politics.

The study described the dynamic use of sociocultural and contextual factors in delivering the campaign message. Being a part of Ambode's strategy, the popular music video was made available to citizens through traditional and new media platforms but the current analysis is based on downloads from YouTube. The research objectives are mainly two-fold: To describe and analyse 'Ambo-Gbabe' music video context, and the sociocultural strategies used in framing the campaign message. Exploring music for electioneering is imperative. The goal is to influence electorates. The relevance of political campaign music videos, therefore, lie in the notion that they are a more persuasive strategy towards the target audience (Wardani et al., 2017).

Akinwunmi Ambode, used Ambo-Gbabe music video to intensify his campaign message during the 2015 general elections. The competitive political environment and the intention to defeat his main opponent in the Peoples Democratic Party (PDP), necessitated the inclusion of music campaign to reach the diversified Lagos audience. Being an informative and entertaining campaign spectacle, music was structured to convey the candidate's political manifesto to Lagosians using popular, cultural and emotional appeals. Deployment of music video is crucial because it can effectively build perceptions through elements of text, image, and music (Wardani et al., 2017). The entertainment media was, therefore, crucial for political information dissemination.

The widespread-use of music for election is not new (Rehm, 2015; Schimler, 2002; Turino, 2008). It is an innovation of Andrew Jackson, whose music campaign in the U.S. contributed to his victory over three prominent presidential contenders in 1824 (Schimler, 2002). Although politicians use the genre, existing studies on music campaigns are largely focused on legal and historical aspects (Schacter, 2011; Schimler, 2002), musical forms, discursive features and effects (Moore, 2010; Thorson, William \& Clarke, 1991; Titus \& Bello, 2012), and music and politics in Cameroon, Kenya and Nigeria (Nyairo \& Ogude, 2005; Nyamnjoh \& Fokwang, 2005; Obono, 2017). While most of the studies are West based, those in Africa concentrated on the analysis of African music (Okunade, 2010), popular songs and politics (Nyairo \& Ogude, 2005; Nyamnjoh and Fokwang, 2005), and post-independence music (Obono, 2017). They overlooked the sociocultural framing and context of music video campaigns in Nigeria, hence, the dearth of information on music for political advocacy and mobilisation.

While music communication is conceptualised in this paper as the art of using vocal, written, instrumental or mechanical sounds to disseminate information, political communication is the verbal and nonverbal processes of disseminating purposeful political messages with a view to influencing public opinion. What makes it 'political' is the content and intentions of the message. 
Socioeconomic and political conditions in Lagos contributed to the music video framing. The study would contribute to existing body of knowledge on the use of music for electioneering, with specific focus on Lagos state, located in southwest Nigeria, and Yoruba, the indigenous language of the people.

\section{Music and Political Communication}

The entertainment industry is becoming a prominent platform for political communication, which is the process involving interaction and transmission of information among politicians, news media and the public (Romarheim, 2005).

Being one of the oldest forms of human expression, the American Supreme Court identified music as a form of expression and communication, protected under the First Amendment of the U.S. constitution (Schacter, 2011).

Music and politics have a long history. Their connect is understood along dimensions of the organisation, its legitimation and cultural performance (Street, Hague \& Savigny, 2008). Political music is at the borderline of rhetoric and propaganda (Romarheim, 2005). Its messages are disseminated through multimedia contexts, featuring dance, costume, mime, poetry and drama (Titus and Bello, 2012), hence, music campaigns can be assessed through different media platforms. The outstanding element in traditional African music is its highly developed rhythm.

Campaign language is often characterized and shaped by rhetoric, persuasion, propaganda, metaphor, euphemism, parallelism, jingles and slogans (Aduradola \& Ojukwu, 2013). This is reflected in music campaigns, hence, the recommendation for the use of music in campaign commercials to enhance viewer's experience (Thorson et al., 1991). Popular music shapes politics. In 2002, the song "Unbwogable" played a crucial role in the campaign of the opposition in Kenya (Nyairo \& Ogude, 2005). Despite music's relevance for political communication, much still remains to be known about the relationships among music, politics, politicians and political communities.

Although popular music shapes politics, framing effects may determine election campaigns and outcomes. Media reflection on the views of a candidate may also shape and determine the issues of importance, hence, online issue salience. The use of music for political campaign is important because of its perceived strengths for targeted message delivery. It is a powerful means of disseminating political information to diverse publics by virtue of their locations, social status and literacy levels. Consequently, the study examined music electioneering in order to contribute to knowledge about the creation of political awareness in the framework of mass mobilization. Music is a powerful communication force whose framed contents oftentimes send clear political messages geared towards public sensitization and mobilisation.

\section{Theoretical Framework}

The study was anchored on Framing Theory, which entails drawing attention to certain attributes of the objects of news coverage and the objects themselves (Goffman, 1974). Framing deals with packaging and presentation of 
information to the public through topic selection and portrayal of some elements of reality while undermining others (Entman, 1993). As a process by which aspects of reality are selected and given greater emphasis to define the problem (Entman, 1993), the theory focuses attention and placement of certain events within a field of meaning. Accordingly, music video campaign draws attention to the political message by focusing on some sociocultural issues that will be meaningful to people within the Lagos state axis.

The theoretical foundations and development of framing are located in interpretive sociology, which assumes that people's interpretation of reality and everyday life depends fundamentally on interaction and definition of situations (Ardèvol-Abreu, 2015). For him, framing is located in the four communication elements: sender, receiver, message and culture. Framing takes cognizance of human elements and is situated within sociocultural realities to enhance interpretation. With the aim of achieving a desired communication goal, it behoves the sender to apply cultural images that capture receivers' world views, identities and imaginations to enhance understanding, appeal and sharing of meaningful information between sender and receiver.

Framing constructs social reality. It describes story content within familiar terrains. As an interpretation-driven study, the theory is relevant because the intention of the music video campaign was to focus citizens' attention on key situations within a sociocultural field of meaning. Frames highlight some aspects of reality at the expense of others. They enable simplification, prioritization and narration of events for quick sorting, interpretation and evaluation (Norris, McQueen \& Cutler, 2003). Built through selection, emphasis, and exclusion criteria, frames facilitate message understanding and provide keys for interpreting reality (Gitlin, 1980). Framing of the music video is expected to highlight specific issues for easy assessment, comprehension and interpretation of the campaign message. Based on its importance for information delivery, communication professionals use frames to tell a story, organise ideas, link stories, and build a historical narrative across time and political space (Ardèvol-Abreu, 2015; MCT, 2017).

Music campaign is framed through historical narratives, meaningful constructs and interpretive frameworks for human identification, easy access and comprehension of political messages by the heterogeneous Lagos publics. The frames used in packaging the campaign story are expected to give meaning, simplify reality and maintain public interest as suggested by Valkenburg, Semetko and De Vreese (cited in Ardèvol-Abreu, 2015).

Different types of frames are used in communication. While natural and social frameworks help individuals to interpret and understand data in a wider social context, natural and social frameworks respectively identify events as physical and socially-driven occurrences (Goffman, 1974). Widely used in political communication, strategy frames focus attention on political candidates, their personality, tactics and development of electoral campaign (Rhee, 1997). They use the language of war and game to highlight the human aspects of the campaign but issue coverage focuses in the proposals to deal 
with social problems (Ardèvol-Abreu, 2015; Rhee, 1997). Due to the diversity of Lagos residents and the need to capture social reality, the music campaign employed multiple frames to capture sender's intentions and speak to the diversified audience.

Framing is a socio-cognitive process that would develop reception of informative message, integration of knowledge and construction of a discursive model (Rhee, 1997). Frank Luntz in Scheufele \& Tewksbury (2007) used the theory to design strategies that would enhance the persuasive power of political communication to influence voting behaviour. In politics, the choice of frames is targeted at persuading the electorates. Concerning the Language of the $21 \mathrm{st}$ century, Frank Luntz observed that what matters most is not what you say but how you say it. Accordingly, the effect of political campaign messages are dependent on the content of the message and mode of presentation. As Rhee (1997) points out, frames feed on cultures, manifest in social discourses and remit implicit contents through a term, metaphor, example, description, argument, picture or reasoning. They activate an interpretive schema in the mind of the receivers based on the choice of words, images, language, figure of speech and cultural representation.

\section{Methodology}

Qualitative research design was used to analyse 'Ambo-Gbabe', the music video campaign of candidate Akinwunmi Ambode of the APC political party, in the 2015 governorship election in Lagos state, Nigeria. The music video was purposively selected based on its popularity and visibility of sociocultural elements. The music featured during the campaign period set by the Independent National Electoral Commission (INEC), 30 November 2014 to 29 February 2015. The campaign message was subjected to qualitative content analysis, which is a systematic and objective means of describing the research phenomena following creation of categories, concepts, conceptual system, or map (Elo \& Kyngäs, 2008). As an approach of systematic, rule-guided qualitative text analysis, the analysis was expanded to the images and context of music campaigns. The research method is important for the study because of its developed procedures of inductive category development (van Dijk, 1980) and capacity to analyse and interpret data.

Inductive content analysis was used because there are no known studies that have investigated the use of music video for electioneering in a culturally diverse and multi-ethnic megacity in Nigeria. It is analysis of texts within the context of communication, following a non-quantification step by step model. Inductive analysis was adopted because the approach allows the detection of frames or reasoning devices, including, metaphors, examples, descriptions, arguments, images and arguments, which may be explicit or implicit (Van Gorp, 2007). The analysis of the phenomenon began by choosing elements that can operate as framing strategies. Identification of frames included text and attributed meanings. The frames used for analysis emerged from the music video. Reasoning and interpretation was based on the latent content, which 
emerged from associations between the framing elements, including images, metaphors and arguments.

The unit of analysis was the music video. The process involved three main phases: preparation of data, organization of data, and reporting of results. Preparation entailed collecting suitable data for content analysis and making sense of it. Organization included open coding, creating categories, and abstraction. Reporting is achieved through systematic presentation, paying attention to the study objectives and connections among variables. The data was reduced to concepts that could describe the research phenomenon.

The early phase of data collection contributed to concept development. The intent and content of the music video were examined, taking cognizance of the political and sociocultural context of communication. Audio-visuals, textual, contextual and interpretive analysis were performed to retrieve explicit, inductive and deductive political information. It described the language, figures of speech, video structuring, symbols, and dance, among other communication styles employed. In his book Frame Analysis, Fairhurst and Sarr (Goffman, 1974) presented metaphor, stories, tradition, slogans, jargons, catchphrases, artefacts, contrast and spin as some framing techniques that are used to create a framework in peoples' mind that would make them think about the issues as the media would want them to. News frames help establish the literally understanding and widespread interpretation of events (Entman, 1993). Accordingly, the frames in 'Ambo-Gbabe' would facilitate message processing, understanding and interpretation.

'Ambo-Gbabe' music video was accessed from YouTube. It ran for 3 minutes and 42 seconds. Following the analytical framework, the video was listened to, viewed, and reviewed for internalization of the message before transcription, translation and interpretation by the principal investigator and two trained research assistants, who have competence in the languages used for communication. This ensured analysis of the content and intent of the campaign message. It described the melodrama, figurative expression, sociocultural context and artefacts within the methodological framework.

The analysis began with an overview of the music video. Specific attention was paid to the latent and patent contents, linguistic forms, and context and sociocultural frames. English, Nigerian Pidgin English, Yoruba, and Igbo were the languages of expression. These data sets were converged and thematically analysed. While text and pictures were used to explain the sociocultural frames, the strength of the analysis lie in the use of investigator and data triangulation. Verbal and visual sociocultural frames would increase understanding and interpretation of the campaign message.

\section{Results}

Music campaigns are increasingly used in Nigeria during election. Their role is to inform, inspire, motivate, energize a political campaign and connect people of different social backgrounds (Street et al., 2008; Turino, 2008). During the 
2015 governorship elections in Lagos, 'Ambo-Gbabe' used sociocultural frames to inform and motivate voters.

\section{Synopsis of 'Ambo-Gbabe' music video}

'Ambo-Gbabe' is a melodramatic performance used by Akinwunmi Ambode, the All Progressives Congress (APC) governorship candidate in Lagos state, to capture the essence of the 2015 campaign. The video literally used real life scenarios of the commercial transport system in Lagos to move people from one location to another. Individuals that constitute the popular transport business - driver, bus conductor and passengers - featured in the movement. The conductor called on passengers to enter the bus with "change", that is, the exact transportation fare while the driver took off to their desired destination. This is the literal presentation of the melodrama but it is an allegory of politics in Lagos state. It contextualises the main message of Ambo - Gbabe, which means, we are coming, just take it, there is nothing anybody can do against it. This political movement corresponds with the popular transportation dynamics in the state.

Metaphorically, the video highlighted the character trait of the contestant and the potential benefits of his tenure to citizens. Framed through relevant sociocultural imageries and figures of speech, the music campaign message was made comprehensible. The political views were expressed through popular scripts, sounds, symbols, settings, and dance, to expose the public to the candidate's political agenda. The video used a combination of dramatology, song, proverb, incantation and rap to present the message.

The song began with the chorus, which captures the intent of the campaign. Written in free verse and arranged in stanzas, the chorus was repeated six times to project the dominant campaign message. Interjection of the chorus at different intervals emphasises the core message with the words 'Ambode' and 'ambo' featuring throughout the stanzas to drive the message and facilitate recall. The song is preceded by a dramatic prelude. The framing may be productive in a political environment with multiple contenders. Analysis of the music reveals the dynamics of music for electioneering.

\section{Context and use of Music Campaign}

The music video is a performance by popular Nigerian music artistes - Yemi Alade, Flavour, Ice Prince, M.I., Olamide, Banky W. and Dammy Krane from the three major Nigerian ethnic groups (Ibo, Yoruba and Hausa). Their participation in the campaign video appeal to popular culture to gain electorate attention, especially among the youth, lower class and middle class, who have a flair for popular music. Framed to capture the plural ethnic composition of Lagos state, cultural, linguistic and sociodemographic mix of actors were deployed. The language, imagery, dressing, lyrics, and speech mirrored the existing social lifestyle and structures in the state. While populism was the adopted campaign strategy, melodrama intensified music effects. The concepts 
and images of the music video are rooted in familiar communication apparatus and sociocultural context.

The prelude to the song reveals the mood of the people and the value of interaction and integration. As projected throughout the performance, stakeholders dramatized different roles but with a singular vision. Using the imagery of Lagos state transportation system, the conductor would usher passengers into the bus while the driver would take them to 'Success Avenue'. Passengers desire to reach their destination on time. This scenario symbolises speedy actualisation of Ambode's political vision of 'success' and 'change', the APC slogan. The motion and flux that is in the heavy dance and transportation represent the regular movement, busy activities and living in Lagos. The rhythms, beats, languages, sounds, and images are a reflection of the lifestyle of Lagosians, hence, the music video is rooted in the salient impulse and ethos of the real composition of the state, showcasing the mood of the city. Exploitation of the natural setting is for familiarization, integration, and facilitation of the message. Lyrics, instrumentation, and performance reinforce this, revealing the transactional nature of communication among residents, who interact despite their sociocultural differences.

The music video adumbrates ethnic diversity and complementarity. The heterogeneous composition of the population emphasizes attainability of political success with human support. The message of the campaign is communicated through proverbs, incantations, and figurative expressions. It used the genre of current street music and popular music artistes to broadcast the vision of Ambode. The synthesis of the campaign, 'Vote Akinwunmi Ambode for governor of Lagos State', is written at the end of the video, encapsulating the goal of the ensemble. Sounds and imageries are used to enhance exposure to, comprehension of and interpretation of the political message. The campaign is expected to increase message visibility, retention and political awareness.

The music video expressed ideas through descriptive, declarative, emotive, concise, and precise vocabulary. The song is presented in a simple but clear style. The propagandist tune displays the fundamental belief in prosperity and posterity. It communicates progress, movement, vigour, among others to appeal to residents. The use of repetition is to reinforce the message as exemplified in the transcribed chorus:
Ambo oo, ambo!
Ambo oo, ambo!
(We are coming, we are coming)
Eko sese bere ni o
(We are coming, we are coming)
Ambo o!
(Lagos has just started)
(We are coming)

The song is value laden as it expresses political ideas focusing on the desirable quality of life of Lagos State residents, including happiness and socioeconomic rejuvenation. The music used cultural images to attend to societal expectations. It conveys patent and latent meanings. Literarily, 'Ambo' means 'we are coming' but it is also a shortened cast of 'Ambode'. The strategy of using part 
of the name of the contestant as title and lead of the song is to focus attention on the candidate. This framing may bring about easy recall of the message and candidate's name to eliminate identity crisis. While the song may enhance interactional and transactional communication in the state, the music video could provide cognitive knowledge that would inform and structure political reality.

\section{Sociocultural Framing of Music Campaign Message}

The framing of 'Ambo-Gbabe' music video was socially and culturally-driven, using images, performances, occurrences and structures that reflect the general ambience of Lagos state. Strategic frameworks, including sociodemographic, spatial, cultural, language, among other communication artefacts, were deployed to help identify events and readily convey political information. The term, 'ambo' framed Ambode as a team player, a visionary, and an active person who delights in working with others. He is projected as upholding collectivist culture not individualism or egocentrism.

Portrayed as possessing the African communal value system of group solidarity, cohesiveness was reflected in the harmonious interaction of singers, dancers and transporters while collective performance of actors from diverse sociocultural backgrounds conveyed team spirit, connotatively labelling Ambode as a team builder. Characterisation of his communal personality is manifest in the music video lyrics and performance as captured in the stanza containing the Yoruba proverb (translated):
A child's hand does not reach the rafter
Elder's hand cannot enter a jar
Children are wise, elders are wise
With that Lagos is found

This proverbial expression shows the relevance of all people for successful governance. It emphasizes collaboration, alluding to Ambode's intention for an all-inclusive government. Highlighting the cultural relevance of all persons in nation-building, the intent of the message may appeal to and capture citizens' interests, thereby increasing the candidate's popularity. The relevance of young people was projected. This frame insinuates that the youth will not be side-lined in Ambode's government as reflected in the lyrics, beats, dance, sound, instrumentation, age, popular Nigerian artistes, among other images that were strategically framed for this sociocultural appeal. The featured musicians would attract attention and activate political participation.

Success is a product of collective action. Actualization of political success in this heterogeneous state was hinged on collaboration of all sociocultural groups, hence, the framing of campaign video using a blend of indigenous musicology and contemporary music. The video highlighted ethnic resonance. Ethnomusicology would easily inform, persuade, and mobilize the public because the sound of the campaign music is not sophisticated but populous and 
falls within the genre of current street music. Selection of language, dressing, dancing, and other nonverbal cues, were geared towards this goal.

The campaign used four languages because of the plural ethnic composition of Lagos state. Multilingual structure of the music video does not only identify with the linguistic composition of the state but could increase message consumption among diverse groups. This would ensure penetration of the message to all residents, irrespective of their linguistic backgrounds, competences, and sociodemographic factors. Within this framework, the level of integration, assimilation and communication would be high as the musicology relates to the demographic ecology of Lagos.

Song and dance are at the centre of music campaigns. The choreography and dance are appropriate because citizens are familiar with and exposed to this mode of leisure and entertainment. Adopting 'shoki' and 'skelewu' dance (Figure 1) would attract public attention, facilitate political information dissemination and enhance message awareness, particularly among young people as they could readily identify with and connect to these modes of popular dancing. Framed with contemporary Nigerian music, the video reveals the place of ethnomusicology in setting the political agenda.
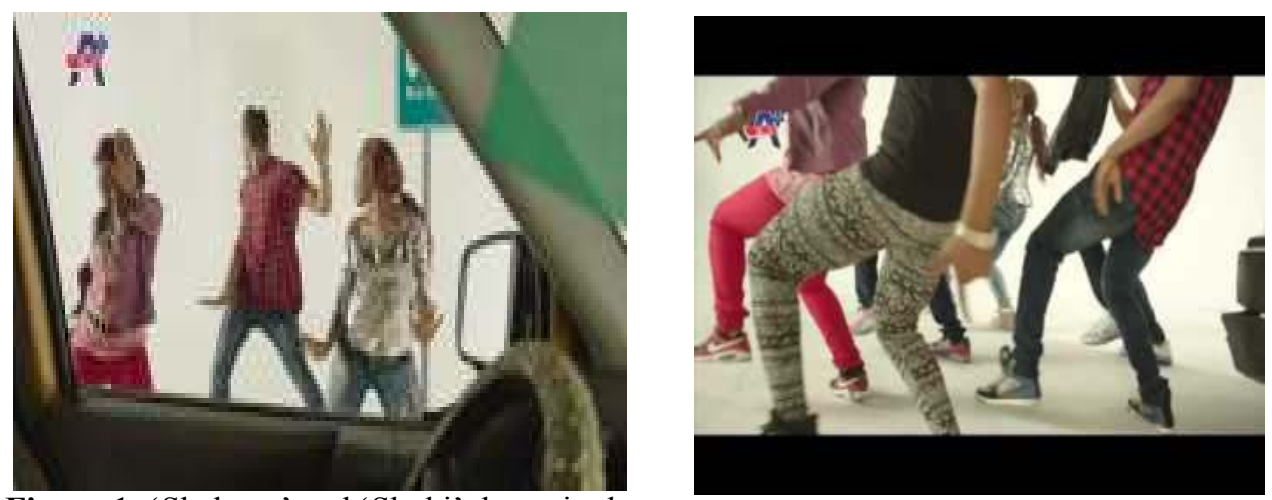

Figure 1: 'Skelewu' and 'Shoki' dance in the music campaign video

Source: Ambo Google images (2015)

Combination of popular music artistes, popular dance and popular yellow bus transport system is a mass-imbued rhetoric. It gave Ambode's campaign a populist appeal, framing him as a man of the masses and one who would use indigenous structures to build the state. The vehicle, the main means of public transportation in Lagos state, was used in the video to convey passengers (Figure 2). The bus symbolises movement not stagnation, suggesting the candidate's intention to build upon existing social structures and improve the legacies of his predecessor, Governor Babatunde Raji Fashola. 


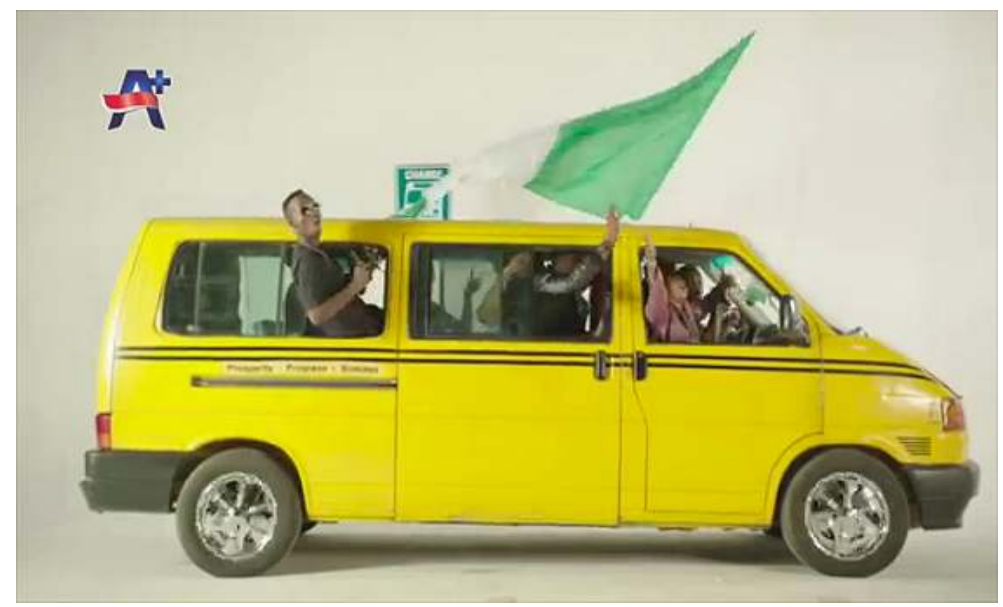

Figure 2: Conventional Lagos transportation bus Source: Ambo Google images (2015)

A schema of good governance, unity and peaceful co-existence was created. Artists, language, lyrics, social groups, and cultural ideologies emphasize 'All of us own Lagos', reflecting the plural nature of the state. The expression of unity of spirit is revealed in the nonverbal structures and verbal utterances in the video, thus:

$$
\begin{array}{ll}
\text { Gbogbowa la l'Eko } & \text { (All of us own Lagos) } \\
\text { Ajo ma jegbadun } & \text { (We will enjoy together) } \\
\text { Gbogbowa la l'Eko o } & \text { (All of us own Lagos, yes) }
\end{array}
$$

This framing is consistent with the real mind-set of most residents, who view themselves as Lagosians, despite their ethnic origins. For affirmation, the video conceptualised Ambode as a unifier, not alienator, of different cultural, religious and ethnic groups. The song also projected the benefits that would accrue to citizens by virtue of Ambode's election. The dramatized personalization shows Ambode's human side, hence, citizens' unreserved trust for him, as sung:

I've been living in Lagos State

Better tomorrow for me and you

I believe in Ambode

He can make this Lagos dream come true

Knowledge of a society is important for successful electioneering. Peoplesensitive campaigns would enhance accurate decoding and understanding of political messages. Accordingly, projection of the expectations of most Lagosians are reflected in the campaign 'story', which promises to move residents from 'Glory to glory, grass to grace' and '...from nothing to something, zero to hero.' This existentialist paradox attended to the hopes of people for better living conditions by exploiting their messianic aspirations. It 
expressed the dream of the 'Promised Land', connoting Ambode's desire for Lagosians to 'conquer,' 'win' and 'rise like an elevator.' Projection of a blissful future encapsulates the hopeful ethos of the city, using a combination of religious, cultural, economic and human-interest frames. While human interest frames draw the message closer to citizens, economic frames emphasize economic rejuvenation following the depressing economy. There is an expectation of 'new enjoyment', 'progress', and 'better tomorrow'.

The exploitation of religious frames to captivate human emotions and solidarity is anchored on the spirituality mind-set and religious-inclinations of people. Some of the lyrics, proverbs, rap, incantation and appearance of actors evoke diverse religious sentiments. The music video ensures easy reach of the message to rural and urban dwellers, young and old, and among people of different social, cultural and religious backgrounds. The Yoruba incantations are figurative to invoke supernatural favour toward the candidate as revealed in the intercessory prayers and expressions of faith, thus:

E dakun e ma je o wole (Please, don't let it drag)

Aki i f'omo ore b'ore (We don't use for sacrifice the child of the oracle)

Awon iyami nbe leyin wa (The mothers [witches] support us)

E e le t'Ambode mole (You can't trample Ambode)

Situated within cultural belief systems, the power of positive thinking was also invoked:

Let me tell you what I mean

Won $\mathrm{n}$ b'onimi du'mi

(We don't wrestle a thing with its owner)

Awon eeyan Tinubu (People of Tinubu -Literally, from the ocean)

Eti mo p'eja lonibu (Know that the ocean belongs to fish)

Prominence of the religious frame has moral and spiritual implications as summarised in the Christian philosophy of 'race' and 'cross' projected in the music's lyrics: 'We're winning the race, To stand out on the cross'. Exploitation of traditional religion and Christianity captures the diverse religious affiliations and sentiments in Lagos.

The song was also cast to appeal to the large Ibo population in Lagos through the use of Igbo language and metaphors. Their rendition emphasized unity, love and support, demonstrating the general spirit of collaboration and African value systems:

Anyi ekwego

Papa Mama ekwego

Brother, sister ekwego

... Anyi choro Ambo
(We have agreed)

(Father and mother have agreed)

(Brother and sister have agreed)

(We want Ambo) 
The presumption is that Ambode's victory will bring about 'better life', including good salaries and joy. Other figurative expressions used to frame the campaign message, included: a play on words (success, change), code switching (We dey come, better igbadun, maka ezigbo pay, pelu change o!), simile (rise like an elevator), alliteration (Who no know go know), and metaphor (Ambo na the way). Situational and metaphorical code-switching was based on the multilingual character of Lagos and would appeal to the social variables of the population to produce rhetorical effects.

'Ambo-Gbabe' music video was framed with sociocultural element to gain attention of Lagos residents. Rhetorical devices in the ensemble would enhance political message dissemination, comprehension and interpretation. Rooted in languages, people and belief systems, sociocultural frames expressed the political message of the political figure, revealing the relationship between culture, people and communication in the Nigerian political field. Framing, therefore, took cognizance of sociocultural structures and projected music's ability for relational and transactional communication. It could serve as a means of increasing public information and knowledge base.

\section{Discussion and Conclusion}

The use of music for political communication is gaining more prominence in the Nigerian social field. Situated within the domain of popular music and indigenous value systems, music video campaigns are integral to draw attention of specific populations. As a political communication medium, music videos showcase the relationship between popular culture and society, and enable the sharing of ideas, intentions, and meanings among political actors. Political music videos are effective campaign tools for influencing human thoughts and feelings and are designed for visual perception (Wardani et al., 2017).

Music campaigns have intellectual, emotional and interactional properties. Videos portray mental images that enrich political information, hence, music transcends entertainment to presentation of sociocultural and ideological issues (Obono, 2017). Its rendition in multiple languages would enhance accessibility and comprehension of the information by a heterogeneous audience. Integration of party slogan, propagandist tune, and literary devices brought to prominence the campaign message of the political figure.

Availability of the music campaign in indigenous and traditional communication was strategic to spread information beyond urban centres, however, its appearance on YouTube was necessary as new opportunities for political campaigns have been created through social media (Obono, 2016). Such technological communication developments would enhance message visibility and facilitate political information acquisition, partly because electorates are becoming more politically conscious and politicians are getting more sophisticated. Advancement in communication and information technologies provide new avenues for reaching the masses with political messages. 
Music campaigns construct images that play on audience's emotions. Portrayal of Akinwunmi Ambode as a humble man, a team player, a man of the masses and a care-provider lies within emotional appeal construct. More of his human qualities were highlighted relative to his campaign policies. This finding is consistent with McNair's (2011) submission of the framing of American campaigns. Highlighting a positive image of a candidate may create positive impressions that would impact on the consciousness of electorates, hence, image framing would appeal to electorates' emotions and intellect.

Music captures the essence of information dissemination and plays a pivotal role in electioneering. It can readily spread a political message to different strata of the population. Political communication employs religious, economic, human interest, and cultural frames to captivate human emotions and conjure the spirit of solidarity. Using context-specific communication elements would ignite message understanding. Through image and text, actors in the video display common behaviours in everyday life, making the audience to feel as if they are a part of the campaign cast (Wardani et al., 2017).

Sociology of communication is implicated in music campaign as messages are framed to suit the sociocultural context of electorates. The success of a music campaign is determined by the level to which the message is adapted to existing societal values, norms, mores, beliefs and communication systems. Human sensitivity and cultural ideologies would ignite emotional appeals that remain relevant to communication. While entertainment draws popular attention, musical expressions provide the public with political information needed to advance the stance of the candidate. In other words, music campaigns express thoughts that can affect human feelings, decisions, and actions. Electioneering music videos are inseparable from sociocultural values and ideologies.

The study, however, is location-specific: Lagos State in Nigeria. A limitation in this study is that it is about a given political environment. The results, therefore, cannot be generalised in locations whose population makeup, diversity, and other factors differ from that of Lagos State. Scholars may in future use the same approach to study other areas where music videos might be used for political campaigns. While the current study is limited in scope, further research can conducted to examine human perceptions about the music video and the influence of sociocultural strategies and frames on the election.

\section{References}

Aduradola, R.R. \& Ojukwu, C.C. (2013) Language of political campaigns and politics in Nigeria. Canadian Social Science, 9(3): 104-116, doi:10.3968/ 1923669720130903.9650.

Ardèvol-Abreu, A. (2015) Framing theory in communication research in Spain: Origins, development and current situation. Revista Latina de Comunicación Social, 70: 423-450, doi:10.4185/RLCS-2015-1053. 
Elo, S. \& Kyngäs, H. (2008) The qualitative content analysis process. Journal of Advanced Nursing, 62: 107-115.

Entman, R.M. (1993) Framing: toward clarification of a fractured paradigm. Journal of Communication, 43(4): 51-58.

Gitlin, T. (1980) The Whole World is Watching: Mass Media in the Making and Unmaking of the New Left. Berkeley: University of California Press.

Goffman, E. (1974) Frame Analysis: An Essay on the Organization of Experience. New York: Harper \& Row.

Google Images (2015) Video: Ambo-Gbabe. Retrieved from https://www.360nobs.com/2015/02/video-ambo-gbabe-ft-ice-prince-m-i-olamide-banky-wyemi-alade-dammy-krane/.

McNaire, B. (2011) An Introduction to Political Communication. New York: Routledge.

MCT (2017) Framing theory. Retrieved from: https://masscommtheory.com/theory-overviews/framing-theory.

Moore, J. (2010) The impact of visual-music interaction on music perception: The influence of agreement and disagreement. Unpublished Master's Thesis, Baylor University, Texas.

Norris, D., McQueen, J.M. \& Cutler, A. (2003) Perceptual learning in speech. Cognitive Psychology, 47: 204-238.

Nyairo, J. \& Ogude, J. (2005) Popular music, popular politics: Unbwogable and the idoms of freedom in Kenyan popular music. African Affairs, 104/415: 225- 249.

Nyamnjoh, F.B. \& Fokwang, J. (2005) Entertaining repression: Music and politics in postcolonial Cameroon. African Affairs, 104/415: 251-274.

Obono, K. (2016) The Architecture and use of social media in the 2015 Nigerian general elections. The Nigerian Journal of Communication, 13(1): 47-78.

Obono, K. (2017) Music and political communication in post-independence Southwest Nigeria. In A.B. Ekanola \& D. Adeyanju (Eds.). Topics in Humanistic Studies, Ibadan: Faculty of Arts, University of Ibadan, pp. 129148.

Okunade, A. (2010) Comparative studies of Egba palace music. Thesis. Institute of African Studies, University of Ibadan, pp. 198.

Rehm, R. (2015) The Role of Music in Presidential Campaigns. Retrieved from: http://thedianerehmshow.org/shows/2015-09-03/the-role-of-music-in-political-campaigns.

Rhee, J.W. (1997) Strategy and issue frames in election campaign coverage: A social cognitive account of Framing effects. Journal of Communication, 47: 26-48.

Romarheim, A.G. (2005) Definitions of Strategic Political Communication. Norwegian Institute of International Affairs.

Schacter, S. (2011) The Barracuda Lacuna: Music, political campaigns, and the First Amendment. The Georgetown Law Journal, 99: 571-604. 
Scheufele, D.A. \& Tewksbury, D. (2007) Framing, agenda-setting and priming: The evolution of three media effects models. Journal of Communication, 57: 9-20.

Schimler, S. (2002) Singing to the oval office: A written history of the political campaign song. Retrieved from http://www.presidentelect.org/art_schimler_singing.html.

Street, J., Hague, S. \& Savigny, H. (2008) Playing to the crowd: The role of music and musicians in political participation." British Journal of Politics and International Relations, 10(2): 269-285, -doi:10.1111/j.1467-856X.2 007.00299 .

Thorson, E., William, G. \&. Clarke, C. (1991) Effects of issue-image strategies, attack and support appeals, music, and visual content in political commercials. Journal of Broadcasting \& Electronic Media, 35(4): 465486.

Titus, O.S. \&. Bello, O.A. (2012) Musical forms in Songs for political mobilisation during 2011 General Elections in Nigeria. International Journal of Humanities and Social Science, 2(13): 166-173. Retrieved from http://www.ijhssnet.com/journals/vol_2_No_13_July.

Turino, T. (2008) Music as Social Life: The Politics of Participation. Chicago: University of Chicago Press.

Van Gorp, B. (2000) The constructionist approach to Framing: Bringing culture back in. Journal of Communication, 57: 60-78.

van Dijk, T.A. (1980) Macrostructures. Hillsdale, N.J.: Erlbaum.

Vanguard (2015, February 25) Celebrities, technology give Nigerian election campaign upgrade. Vanguard Online. Retrieved from http://www.vanguardngr.com/2015/02.

Wardani, W.G.W., Listya, A. \& Winarni, R.W. (2017) Political campaign's music video as a strategy for forming perceptions. International Journal of Scientific \& Technology Research, 6(11). 